\title{
ĐỔI MỚI PHƯƠNG PHÁP ĐÀO TẠO KẾ TOÁN BậC ĐẠI HỌC PHÙ HỢP VỚI YÊU CẦU CẢI CÁCH KẾ TOÁN
}

\author{
CAO THỊ CẢM VÂN \\ Truờng Đại học Công nghiệp Thành phố Hồ Chí Minh \\ caothicamvan@iuh.edu.vn
}

Tóm tắt. Đổi mới công tác đào tạo kế toán là một yêu cầu cấp thiết của hầu hết các trường đại học tại nhiều quốc gia nói chung và tại Việt Nam nói riêng nhằm hướng tới việc cung cấp nguồn nhân lực chất lượng cao phù hợp với yêu cầu quản lý của nền kinh tế phát triển và hội nhập. Có thể thấy rằng, trong những năm qua, công tác đào tạo kế toán ở các trường đại học của Việt Nam đã có những chuyển biến tích cực, tuy nhiên không thể phủ nhận rằng vẫn còn khoảng cách khá lớn giữa yêu cầu của xã hội và chất lượng nguồn nhân lực được cung cấp. Do đó, công tác đào tạo kế toán cần phải được xem xét từ quan điểm đến phương thức thực hiện sao cho phù hợp với yêu cầu đổi mới. Trong phạm vi bài viết, trên cơ sở nghiên cứu thực trạng, người viết sẽ trao đổi một số ý kiến liên quan đến công tác đào tạo kế toán bậc đại học tại Việt Nam hiện nay.

Tù khóa. Đổi mới công tác đào tạo kế toán; hội nhập kinh tế

\section{THE UNDERGRADUATE ACCOUNTING TRAINING RENOVATION MATCH ACCOUNTING REFORM REQUIREMENTS}

\begin{abstract}
Renovation of accounting training is an urgent requirement of most universities not only in many countries but also in Vietnam with the purpose provides high quality human resources in line with the requirements ofintegration and developmenteconomy. There is a fact that in the past few years, accounting training in Vietnamese universities has made positive changes. However, it cannot be denied that there is still a significant gap between the social needs and the quality of human resources; therefore, accounting training needs to be considered from viewpoint to the implementation methods in order to meet the reform requirements. Within the scope of the research, based on the actual situation, the author will discuss some ideas related to accounting training in Vietnamese universities.
\end{abstract}

Keywords. Accounting training renovation; the context of integration international

\section{1. ĐặT VẤN ĐỀ}

Nếu như hội nhập là một động lực quan trọng thúc đẩy sự phát triển kinh tế làm tăng sức mạnh tổng hợp quốc gia, thì đó cũng chính là một thách thức lớn đối với công tác đào tạo kế toán về tính chuyên nghiệp, kỹ năng và kiến thức để đáp ứng yêu cầu ngày càng cao của xã hội theo xu hướng hội tụ kế toán trên thế giới. Đối với Việt Nam, trong thời gian qua chính sách đa phương hóa, đa dạng hóa, mở cửa hội nhập đã tác động mạnh mẽ đến nhiều lĩnh vực kinh tế, theo đó, các công cụ quản lý tài chính trong đó có kế toán đã từng bước được đổi mới sâu sắc và toàn diện theo yêu cầu phát triển của một nền kinh tế mở. Đồng thời, trong điều kiện cơ chế kinh tế thị trường, kế toán trở thành một ngành, một lĩnh vực dịch vụ hỗ trợ quản lý kinh doanh trong phạm vi từng quốc gia, từng khu vực và thế giới. Thực trạng này đã mang lại áp lực đối với công tác đào tạo kế toán Việt Nam, bởi vì theo nhận định của nhiều chuyên gia, số lượng và chất lượng nguồn nhân lực kế toán mang tầm quốc tế của Việt Nam còn khá khiêm tốn, đây sẽ là rào cản lớn trong hội nhập kinh tế của Việt Nam. Do đó, đổi mới công tác đào tạo kế toán nhằm nâng cao chất lượng nguồn nhân lực được xem là nhiệm vụ trọng tâm đối với các trường đại học hiện nay.

\section{SỰ CÀ̀ THIẾT PHẢI ĐỔI MỚI CÔNG TÁC ĐÀO TẠO KẾ TOÁN}

+ Xu hướng hội tụ công tác đào tạo kế toán: 
Trong một nghiên cứu về khuynh hướng toàn cầu hóa công tác đào tạo kế toán, Karreman \& ctg (2007) cho rằng hội nhập kinh tế đã tạo nên một áp lực cho việc đổi mới và hội tụ trong đào tạo kế toán, bởi hội nhập đã đưa thế giới ngày càng xích lại gần nhau hơn thông qua các mối liên kêt và sự phụ thuộc lẫn nhau trong quan hệ kinh tế, từ đó phát sinh nhu cầu hòa hợp kế toán trong phạm vi quốc tế và khu vực, nhằm tạo nên một khuôn khổ pháp lý kế toán thống nhất trên toàn thế giới. Công tác đào tạo kế toán từ đó cũng phải được thay đổi từ chương trình đào tạo, phương pháp giảng dạy để có thể thích ứng với yêu cầu mới và có thể cạnh tranh trong phạm vi khu vực và thế giới.

\section{+ Sụ ra đò̀i của tiêu chuẩn đào tạo quốc tế(IES):}

Hiện nay, Ủy ban Tiêu chuẩn đào tạo Quốc tế (IAEBS) - một tổ chức được thành lập bởi Liên đoàn kế toán quốc tế (IFAC) đã ban hành 8 tiêu chuẩn đào tạo quốc tế (IES) IES tập trung vào sự phát triển và đánh giá năng lực. Người kế toán phải được trang bị không những kiến thức chuyên môn mà cần phải trau dồi các kỹ năng như: kỹ năng trí tuệ, kỹ năng kỹ thuật, kỹ năng giao tiếp và truyền đạt thông tin,...nâng cao giá trị đạo đức và thái độ nghề nghiệp, IES được xem là tiêu chuẩn để so sánh chất lượng đào tạo kế toán và sự thừa nhận lẫn nhau về trình độ kế toán giữa các quốc gia. Cho đến nay tất cả các tổ chức thành viên của IFAC đều nhất trí đổi mới chương trình đào tạo theo IES (Verkruijsse, 2012).

\section{PHƯƠNG PHÁP NGHIÊN CÚU:}

Nghiên cứu này được thực hiện qua hai bước: (i) Phân tích các tài liệu nghiên cứu; khảo sát thực trạng công tác đào tạo kế toán của các trường đại học tại Việt Nam hiện nay; Phỏng vấn chuyên gia và các đối tượng nghiên cứu; xây dựng bảng câu hỏi để tiếp tục thực hiện các bước nghiên cứu tiếp sau. (ii) Phương pháp nghiên cứu định lượng được sử dụng nhằm đo lường mức độ tác động làm cơ sở cho một số đề xuất của nghiên cứu.

\section{THỰC TRẠNG CÔNG TÁC ĐÀO TẠO KẾ TOÁN TẠI VIẸT NAM}

Với chủ trương đổi mới giáo dục đại học Việt Nam giai đoạn 2006 - 2020 theo Nghị quyết Số 14/2005/NQ-CP của Chính Phủ, trong những năm gần đây giáo dục đại học nước ta đã có những chuyển biến, tích cực. Phần lớn các trường đại học đã chú trọng đến việc nâng cao chất lượng đào tạo, theo thống kê của Cục Khảo thí và kiểm định chất lượng tính đến ngày 30/6/2016 đã có 207 trên tổng số 223 trường đại học trong cả nước đã hoàn thành báo cáo tự đánh giá, trong đó 13 trường được tổ chức Kiểm định chất lượng giáo dục đánh giá ngoài, 2 trường được công nhận đạt tiêu chuẩn chất lượng. Trong số các trường đại học hiện nay, có hơn $50 \%$ trường có đào tạo chuyển ngành kế toán, bao gồm các trường thuộc khối ngành kinh tế và kể cả một số trường kỹ thuật. Ngành kế toán gần đây trở thành một ngành dẫn đầu trong khối ngành kinh tế về số lượng sinh viên theo học. Nhìn chung, công tác đào tạo kế toán của Việt Nam trong những năm gần đây được đánh giá có bước chuyển mình, đổi mới đáng kể, về cơ bản đã đáp ứng yêu cầu cung cấp nguồn nhân lực kế toán cho nền kinh tế. Tuy nhiên, trong tiến trình hội nhập, kế toán không còn thuần túy là công cụ quản lý mà phát triển thành một ngành, một loại hình dịch vụ và không chỉ cạnh tranh giữa các đơn vị trong nước mà cạnh tranh với cả các đơn vị nước ngoài. Thực trạng đó, đòi hỏi phải nhìn nhận và đánh giá một cách khách quan về thực trạng công tác đào tạo kế toán tại Việt Nam:

\section{+ Thục trạng về chương trình đào tạo:}

Trong những năm qua, chương trình đào tạo giáo dục đại học nói chung và đào tạo kế toán bậc đại học nói riêng đã có nhiều cải cách, sửa đổi. Mặc dù vậy, chiến lược phát triển giáo dục 2011-2020 của Thủ Tướng Chính phủ cũng đã chỉ ra một số tồn tại của lĩnh vực giáo dục: "Nội dung chuoong trình, phưong pháp dạy và học, công tác thi, kiểm tra, đánh giá chậm đổi mới. Nội dung còn nạng về lý thuyết... chua chuyến mạnh sang đào tạo theo nhu cầu xã hội...". Đây cũng là thực trạng đối với ngành kế toán Việt Nam, nhìn chung chương trình đào tạo kế toán hiện nay chưa gắn kết với nhu cầu thực tế của thị trường, chương trình chú trọng nhiều vào việc ghi nhận sổ sách hơn là phát huy khả năng tư duy sáng tạo của người học. Trong khi đó, cùng với quá trình phát triển kinh tế, vai trò và trách nhiệm của kế toán 
trong các công ty đang ngày càng lớn hơn và đòi hỏi nhiều kiến thức kỹ năng hơn, người sử dụng lao động cũng đặt ra nhiều tiêu chí tuyển dụng và mong muốn nhiều hơn ở người xin việc.

Bên cạnh đó, một trong những hạn chế mà Chiến lược phát triển kinh tế chỉ ra đó là tình trạng mất cân đối trong cơ cấu ngành đào tạo. Thực vậy, theo số liệu thống kê của VietnamWorks về tình hình tăng trưởng nhu cầu tuyển dụng:

Bảng 1: Thống kê tỷ lệ nhu cầu tuyển dụng lao động

\begin{tabular}{|l|c|c|c|}
\hline \multicolumn{1}{|c|}{ Năm } & $\begin{array}{c}\text { Tỷ lệ tăng trưởng nhu cầu } \\
\text { nhân lực chung }\end{array}$ & $\begin{array}{c}\text { Tỷ lệ tăng trưởng nhu } \\
\text { cầu nhân lực kế toán }\end{array}$ & Mức cạnh tranh \\
\hline 6 tháng đầu năm 2014 & $25 \%$ & $69 \%$ & $1 / 103$ \\
\hline 6 tháng đầu năm 2015 & $34 \%$ & $98 \%$ & $1 / 85$ \\
\hline
\end{tabular}

Nguồn: VietnamWorks

Căn cứ kết quả thống kê cho thấy, ngành kế toán có tỷ lệ tăng nhu cầu tuyển dụng khá cao năm 2015 được xếp thứ 3 trong các ngành có tỷ lệ tăng trưởng cao nhất, thế nhưng mức độ cạnh tranh trong ngành vẫn khá gay gắt, cụ thể năm 2014 mức cạnh tranh là $1 / 103$ và năm $20151 / 85$, nghĩa là trung bình cứ một hồ sơ nộp vào vị trí ngành kế toán sẽ phải cạnh tranh với 85 hồ sơ khác, đây là hệ quả của việc phát triển quá nhanh về quy mô, thay vì chú trọng vào chiều sâu để nâng về chất cho nguồn nhân lực kế toán.

Đánh giá chương trình đào tạo là một khâu quan trọng để tìm hiểu xem chương trình có hòan thành sứ mạng, mục tiêu đã đề ra không, hiện nay công tác này chưa thực sự chưa được coi trọng, hầu hết chương trình đào tạo của các trường đại học Việt Nam đã xây dựng chuẩn đầu ra, tuy nhiên, một số trường lại thiếu hẳn bộ tiêu chí để đánh giá kết quả hoặc việc đánh giá chưa được thực hiện nghiêm túc, thiếu sự tham gia của các tổ chức cá nhân liên quan. Theo nghiên cứu của Green (1994), việc xác định chất lượng của giáo dục đại học đại học cần dựa trên các tiêu chí mà các bên có lợi ích liên quan sử dụng, các nhóm lợi ích có liên quan bao gồm: (1) Các tổ chức, các đơn vị tài trợ cho hoạt động giáo dục và đào tạo; (2) Nhóm người sử dụng dịch vụ giáo dục; (3) Nhóm người sử dụng lao động; (4) Nhóm những người lao động trong khu vực giáo dục đại học (Srikanthan và Dalrymymple, 2003). Do đó, việc đánh giá cần phải được triển khai một cách chặt chẽ và minh bạch, có sự tham gia của các bên liên quan để có thể đạt được kết quả mong muốn.

Nhận định về khung chương trình đào tạo của Việt Nam, nhiều chuyên gia đồng tình khung chương trình do Bộ Giáo dục quy định tập trung nhiều đến phần giáo dục đại cương, thời lượng cho các môn học chuyên ngành rất thấp. Khảo sát và so sánh tổng quát chương trình đào tạo của Đại học Illinoise (Hoa kỳ) và chương trình khung của Việt Nam như sau:

Bảng 2: Bảng so sánh thời lượng phân bổ chương trình đào tạo

\begin{tabular}{|l|c|c|}
\hline Kiến thức đào tạo & Đại học Illinoise (Hoa kỳ) & Chương trình khung ĐH Việt Nam \\
\hline Khối kiến thức giáo dục tổng quát & 60 & 64 \\
\hline Các môn cơ sở ngành & 33 & 36 \\
\hline Môn chuyên ngành & 27 & 20 \\
\hline Tồng số tín chỉ & 120 & 120 \\
\hline
\end{tabular}

Nguồn: Illinoise và chuong trình khung đào tạo Ban hành kèm theo Quyết định số 23 /2004/QĐ-BGD\&Đ

Kết quả khảo sát cho thấy, thời lượng kiến thức chuyên ngành của ta so với nước ngoài khá thấp, chương trình chú trọng nhiều vào phần giáo dục đại cương.

Ngoài $\mathrm{ra}$, một số trường đã đưa các môn chuyên ngành sang giảng dạy bằng tiếng Anh nhưng chương trình lại không ràng buộc quy định trình độ ngoại ngữ đối với người học, trình độ ngoại ngữ thấp, chênh lệch cũ̃ng ảnh hưởng nhất định đến chất lượng đào tạo. Kết quả khảo sát sinh viên Đại học Công nghiệp TP Hồ Chí Minh về việc học môn chuyên ngành kế toán bằng tiếng Anh như sau:

- Đối tượng khảo sát: Sinh viên năm thứ 3 (hiện đang học một số môn chuyên ngành bằng tiếng Anh)

- Số phiếu phát ra: 230 phiếu; thu về: 228 phiểu. 
- Kết quả khảo sát:

Bảng 3: Bảng tổng hợp kết quả khảo sát ý kiến sinh viên về việc học các môn chuyên ngành bằng tiếng Anh

\begin{tabular}{|l|c|c|}
\hline \multicolumn{1}{|c|}{ Tiêu chí thống kê } & \multicolumn{2}{c|}{ Kết quả khảo sát } \\
\cline { 2 - 3 } & Số lượng & Tỷ lệ \\
\hline Số sinh viên hiện chưa có bằng ngoại ngữ & 198 & $86,84 \%$ \\
\hline $\begin{array}{l}\text { Số sinh viên hiện đang tham gia các chương trình tiếng Anh } \\
\text { tại các trung tâm }\end{array}$ & 34 & $14,91 \%$ \\
\hline $\begin{array}{l}\text { Số sinh viên cảm thấy gặp khó khăn khi học các môn chuyên } \\
\text { ngành bằng tiếng Anh }\end{array}$ & 184 & $80,7 \%$ \\
\hline $\begin{array}{l}\text { Số sinh viên nhẩt trí quy định trình độ Anh văn tối thiểu khi } \\
\text { tham gia các môn chuyên ngành giảng dạy bằng tiến Anh }\end{array}$ & 189 & $82,89 \%$ \\
\hline $\begin{array}{l}\text { Số sinh viên nhất trí vẫn duy trì giảng dạy các môn chuyên } \\
\text { ngành bằng tiếng Anh }\end{array}$ & 173 & $75,87 \%$ \\
\hline
\end{tabular}

Kết quả khảo sát trên cho thấy, chỉ có $14,19 \%$ sinh viên đang theo học ngoại ngữ tại các trung tâm song song với việc học các môn chuyên ngành bằng tiếng Anh. Phần lớn sinh viên chuẩn bị ra trường mới bắt đầu học, để hợp thức hóa bằng cấp, đây là một thực trạng phổ biến trong sinh viên, vì thế khó khăn để tiếp cận các kiến thức chuyên ngành bằng tiếng Anh là hiển nhiên. Mặc dù vậy, kết quả khảo sát về việc có nên duy trì các môn chuyên ngành giảng dạy bằng tiếng Anh hay không, phần lớn sinh viên đều nhất trí rằng trong xu thế hội nhập kinh tế thế giới và xu hướng hội tụ kế toán điều này là cần thiết $(173 / 228)$. Tuy nhiên, do chưa sắp xếp thời gian một cách khoa học và điều kiện kinh tế nên nhiều em không thể tham gia, vì vậy, để việc học tập các môn chuyên ngành bằng tiếng Anh một cách hiệu quả đề xuất chung của sinh viên là nên quy định chuẩn tối thiểu cần đạt trước khi tham gia, điề̀ này không những hỗ trợ cho việc học tập hiệu quả mà còn mở rộng khả năng tư duy của sinh viên thông qua tìm hiểu các tài liệu nước ngoài để khai thác các khía cạnh của môn học.

Nếu so sánh các kiến thức chuyên ngành của Việt Nam với hệ thống tiêu chuẩn đào tạo quốc tế - IAE thì chương trình đào tạo chuyên ngành của ta kém xa do chưa chú trọng đến kỹ năng nghề nghiệp, giá trị đạo đức, năng lực chuyên môn để người học có thể duy trì và phát triển nghề nghiệp. Một hạn chế đáng kể nữa của chương trình đào tạo kế toán Việt Nam đó là chưa liên kết được với các chương trình đào tạo theo tiêu chuẩn quốc tế, trong khi một số quốc gia chương trình đào tạo đã có bổ sung các học phần mà người học có thể dự thi chứng chỉ CPA do các hiệp hội nghề nghiệp tổ chức.

\section{+ Thục trạng phwơng pháp giảng dạy:}

Trong những năm gần đây, nhiều trường đại học đã đổi mới theo hướng giảm giờ lý thuyết tăng giờ thực hành, bổ sung kỹ năng nghề nghiệp cho sinh viên. Tuy nhiên, trong thực tế vẫn còn nhiều bất cập trong phương pháp giảng dạy, theo đó, phương pháp giảng dạy hiện nay còn nặng về lý thuyết, người học chưa thực sự phát huy được tính sáng tạo và chủ động. Mặc dù nhiều trường đại học đã áp dụng phương pháp giảng dạy tích cực, tuy nhiên hiệu quả chưa cao do người giảng chưa nghiên cứu để vận dụng thích hợp và hạn chế từ khả năng thích ứng của người học.

\section{+ Thục trạng về đội ngũ giảng viên:}

Để người học có khả năng tiếp cận với công việc ngay khi mới ra trường, một đòi hỏi đặt ra đối với giảng viên là phải vừa có kiến thức chuyên môn sâu, vừa phải am hiểu thực tế để có thể cung cấp kinh nghiệm cho người học trong xử lý các tình huống cụ thể. Tuy nhiên, hiện nay không ít giảng viên chỉ tập trung vào lý thuyết, giảng theo giáo trình, chưa gắn kết với thực tế và chưa chú trọng đến việc rèn luyện các kỹ năng cho người học. Các phương pháp giảng dạy tích cực trong thực tế vẫn chưa được vận dụng một cách phù hợp, từ đó, không khơi gợi sự tò mò, kích thích của người học, không mang lại sự hấp dẫn đối với môn học. Việc kiểm soát chất lượng đào tạo chưa được thực hiện ngay trong quá trình giảng dạy, trong thực tế rất ít giảng viên thông qua đánh giá các bài kiểm tra thường kỳ để bổ sung kiến thức kịp thời cho sinh viên. 
Thực hiện chuyên môn hóa trong đào tạo và nghiên cứu theo tiêu chuẩn quốc tế đòi hỏi giảng viên vừa phải có kiến thức chuyên sâu, vừa phải có trình độ ngoại ngữ nhất định, tuy nhiên, phải thừa nhận rằng đây là một hạn chế lớn của đội ngũ giảng viên hiện nay, bởi vì giảng viên trẻ có trình độ ngoại ngữ thì không có kinh nghiệm trong thực tiễn trong khi giảng viên có nhiều kinh nghiệm có học vị thì rất ít người có trình độ ngoại ngữ cao. Bên cạnh đó, công tác nghiên cứu khoa học cũng chưa được chú trọng. Có thể thấy nguyên nhân của việc hạn chế trong nghiên cứu khoa học một mặt xuất phát từ năng lực nghiên cứu của giảng viên, mặt khác là do chính sách đãi ngộ chưa cao nên việc dạy thêm để cải thiện thu nhập khá phổ biến trong giảng viên, chưa kể là một số trường phát triển quá nhanh về quy mô đào tạo nên thời lượng phân cho giảng viên quá cao không còn thời gian để tham gia nghiên cứu.

\section{+ Thục trạng về công tác giáo trình:}

Nhận xét về giáo trình đào tạo kế toán hiện nay nhiều chuyên gia đồng tình rằng phần lớn các giáo trình được viết trên tinh thần các Thông tư hướng dẫn chuẩn mực, ít giáo trình viết theo Chuẩn mực kế toán, vì thế không phát huy được khả năng suy luận và phát triển kiến thức. Ngoài ra, để có thể tiếp cận với các kiến thức chuyên sâu đòi hỏi người học phải nắm vững kiến thức nền tảng, do đó khi thiết kế bài tập theo từng chương cũng cần trên quan điểm từ dễ đến khó, điều này không những giúp người học dễ hiểu mà còn tạo nên sự thích thú trong học tập.

\section{MộT SỐ ĐỊNH HƯớNG VÀ GIẢI PHÁP ĐỔI MỚI CÔNG TÁC ĐÀO TẠO KẾ TOÁN BậC ĐẠI HỌC HIỆN NAY}

+ Xác định mục tiêu đổi mới công tác đào tạo kế toán bậc đại học theo hướng hội nhập, đào tạo nguồn nhân lục có chất luợng cao:

Chúng ta thấy rằng, thế giới ngày nay không ngừng thay đổi, làn sóng toàn cầu hóa và các giao dịch xuyên quốc gia ngày càng phát triển, đã thúc đẩy hội tụ, giảm thiểu sự khác biệt và tiến tới thống nhất khung pháp lý về kế toán trên toàn thế giới. Hòa cùng làn sóng đó, Việt Nam đã thể hiện quan điểm mở cửa hội nhập trong lĩnh vực kế toán, trở thành thành viên thứ 7 của Liên đoàn kế toán các nước ASEAN, thành viên thứ 130 của Liên đoàn quốc tế (IFAC) - một tổ chức có quy mô toàn cầu của các tổ chức quốc gia về kế toán và chính thức trở thành thành viên thứ 21 của Diễn đàn hợp tác kinh tế Châu á-Thái bình dương (APEC). Nhìn chung, trong khuôn khổ các hiệp định hợp tác quốc tế, Việt Nam cho phép các công ty kế toán, kiểm toán, các tổ chức tư vấn tài chính, kế toán nước ngoài đầu tư, hoạt động tại Việt nam. Bên cạnh đó, với Hiệp định thương mại Việt - Mỹ, Việt Nam đã mở cửa thị trường kế toán, kiểm toán cho liên doanh và doanh nghiệp $100 \%$ vốn nước ngoài của Mỹ. Đặc biệt, kể từ sau khi gia nhập Tổ chức Thương mại Quốc tế (WTO), Việt Nam không hạn chế phương thức cung cấp qua biên giới đối với dịch vụ kế toán, kiểm toán, ghi sổ kế toán, dịch vụ thuế, các doanh nghiệp Việt Nam có thể thuê doanh nghiệp kế toán, kiểm toán nước ngoài cung cấp dịch vụ cho mình. Đến đây có thể thấy rằng, từ quá trình toàn cầu hóa và hội nhập kinh tế thế giới, kế toán đã trở thành một ngành, một lĩnh vực thương mại không kém phần quan trọng của từng quốc gia và trên toàn cầu, nghĩa là mọi quốc gia tham gia các hiệp định thương mại sẽ cùng cạnh tranh bình đẳng với nhau trên một sân chơi chung. Trong khi đó, không thể phủ nhận rằng chất lượng nguồn nhân lực kế toán của ta còn thấp, không đủ sức cạnh tranh, trong khi nhiều quốc gia trên thế giới đã nghiên cứu và vận dụng tiêu chuẩn đào tạo quốc tế (IES), từ thực trạng trên, cần xác định mục tiêu đổi mới công tác đào tạo kế toán bậc đại học theo hướng hội nhập là đào tạo nguồn nhân lực có chất lượng cao theo chuẩn quốc tế, không những đáp ứng nhu cầu thị trường trong nước mà còn hướng tới thị trường khu vực và thế giới.

\section{+ Đổi mới chương trình đào tạo theo hướng hội nhập quốc tế:}

Một trong những yếu tố quan trọng góp phần tạo nên sự thành công của hoạt động đào tạo là chương trình đào tạo, chương trình đào tạo tốt, hiện đại sẽ mang lại hiệu quả giáo dục tích cực, kích thích sự tích luỹ kiến thức và phát triển tư duy cho người học. Chúng ta biết rằng, chuẩn đầu ra của chương trình đào tạo được xác định trên cơ sở mục tiêu đào tạo, do đó một khi chuẩn đầu ra thay đổi thì các hoạt động dạy và học cũng phải thay đổi. Từ chuẩn đầu ra của chương trình hoặc của môn học được xây dựng, người giảng viên cần quan tâm đến việc làm thế nào để sinh viên đạt được mục tiêu đó, hay nói khác hơn là thực 
hiện các phương pháp tổ chức giảng dạy một cách có hiệu quả để đạt chuẩn đầu ra kỳ vọng. Tiếp theo đó, đánh giá chương trình đào tạo cũng là một nội dung quan trọng nhằm nâng cao chất lượng đào tạo, bộ tiêu chí đánh giá sẽ được xây dựng dựa trên chuẩn đầu ra của chương trình đào tạo, việc đánh giá phải được thực hiện một cách nghiêm túc, định kỳ và minh bạch, có sự tham gia của các đơn vị liên quan đặc biệt là người sử dụng lao động.

Trong giai đoạn trước mắt, trình độ ngoại ngữ sinh viên còn thấp và chênh lệch, một vấn đề cần lưu ý khi xây dựng chương trình đào tạo đó là cần thiết ràng buộc về trình độ ngoại ngữ đối với người học khi tham gia các môn học chuyên ngành được giảng dạy bằng tiếng Anh, để người học có khả năng tiếp cận với kiến thức chuyên sâu và tạo điều kiện thuận lợi cho người giảng khi khai thác các khía cạnh của môn học.

Với mục tiêu đào tạo nguồn nhân lực có chất lượng cao, đòi hỏi nội dung chương trình phải được đổi mới vừa đáp ứng nhu cầu thị trường lao động trong nước, vừa phải tiếp cận với các chương trình đào tạo tiên tiến trong khu vực và trên thế giới. Nội dung chương trình cần tham khảo, kế thừa các chương trình đào tạo tiên tiến trên trong khu vực và trên thế giới, bổ sung các học phần cần thiết để người học có thể dự thi chứng chỉ CPA do các hiệp hội nghề nghiệp tổ chức.

Xu hướng chung của thế giới đang hướng tới chuẩn đào tạo tiên tiến được thế giới thừa nhận, vì thế sẽ không có gì ngạc nhiên khi ngày càng nhiều quốc gia xây dựng chương trình đào tạo theo tiêu chuẩn đào tạo quốc tế (IES), bởi vì, IES tập trung vào phát triển năng lực của người học, bao gồm kỹ năng nghề nghiệp, giá trị đạo đức và thái độ nghề nghiệp, người học có cơ hội tiếp tục học tập phát triển nghề nghiệp cũng như có cơ hội hội nhập vào môi trường làm việc quốc tế. Với chủ trương mở cửa hội nhập, chắc chắn Việt Nam cũng sẽ không nằm ngoài xu hướng này, vì thế nghiên cứu áp dụng tiêu chuẩn đào tạo quốc tế sẽ là vấn đề đặt ra đối với các trường đại học hiện nay.

\section{+ Đổi mới phương pháp giảng dạy theo hướng chủ động}

Phương pháp giảng dạy chủ động hướng tới việc hoạt động hóa, tích cực hóa hoạt động nhận thức của người học, nghĩa là tập trung vào phát huy tính tích cực của người học, tuy nhiên để dạy học theo phương pháp chủ động thì giảng viên phải nỗ lực nhiều hơn so với dạy theo phương pháp thụ động. Theo đó, người học là trung tâm, được cuốn hút vào các tình huống liên quan đến công việc kế toán của các doanh nghiệp trong thực tế, qua đó quan sát, thảo luận, giải quyết vấn đề theo ý kiến riêng của mình, từ đó khám phá những kiến thức, kỹ năng mới.

Một trong những phương pháp giảng dạy chủ động khá hiệu quả đó là rèn luyện phương pháp tự học cho người học, phương pháp này có ý nghĩa tích cực tạo cho người học, kỹ năng, thói quen và ý chí tự học, thúc đầy lòng ham học và khơi dậy nội lực vốn có trong mỗi con người, vai trò của người thầy lúc này là người hướng dẫn cho người học đi tìm tri thức.

Phương pháp giảng dạy chủ động đề cao vai trò phối hợp học tập giữa cá nhân với học tập theo nhóm. Bởi vì do khả năng tư duy và tiếp thu của mỗi người học là khác nhau từ đó sự phân hóa về cường độ, tiến độ hoàn thành nhiệm vụ học tập tất yếu phát sinh. Trong bối cảnh đó, lớp học sẽ chính là nơi mà người học có thể tự cũng cố kiến thức của mình và nâng cao thêm trình độ hiểu biết, thông qua thảo luận, tranh luận trong tập thể, vì vậy, giảng viên cần tăng thời lượng thảo luận, làm việc nhóm dựa trên các chủ đề mở rộng từ nội dung môn học, thiết kế, tổ chức và hướng dẫn cho người học phương pháp làm việc nhóm. Song song đó, giảng viên còn phải theo dõi các hoạt động của nhóm, qua đó trao đổi, góp ý, gợi mở, động viên, thậm chí làm "trọng tài" khi cần thiết để thúc đẩy khả năng tư duy sáng tạo của người học.

\section{+ Đổi mới nâng cao chất lự̛ng đội ngũ giảng viên}

Có thế nói, vai trò của giảng viên trong đổi mới công tác đào tạo kế toán rất quan trọng, giảng viên vừa phải là người có kiến thức chuyên môn sâu, không ngừng cập nhật các kiến thức mới, vừa phải am hiểu tình hình thực tiễn của các hoạt động chuyên môn trong lĩnh vực kế toán. Không những thế, để có thể tiếp cận với các tài liệu nước ngoài phục vụ cho nghiên cứu và trao đổi học thuật, một yêu cầu đặt ra đối với giảng viên là phải thành thạo ngoại ngữ, có khả năng khai phá các kiến thức mới, bổ sung làm phong phú bài giảng.

Một nhiệm vụ không kém phần quan trọng để đổi mới nâng cao chất lượng đội ngũ giảng viên đó là nhiệm vụ nghiên cứu khoa học, đây được xem là nhiệm vụ trọng yếu hàng đầu đối với các trường đại học để nâng cao chất lượng công tác đào tạo. Có thể nói, đào tạo và nghiên cứu khoa học có mối quan hệ hữu 
cơ với nhau, gắn kết chặt chẽ và bổ trợ cho nhau, nghiên cứu khoa học là hoạt động đi tìm cái mới, cái mới ở đây không chỉ thể hiện trên kết quả nghiên cứu mà còn ở phương pháp khoa học và khả năng ứng dụng phương pháp mới để giải quyết một vấn đề. Do đó, có thể khẳng định rằng cùng với hoạt động giảng dạy, nghiên cứu khoa học sẽ là thước đo năng lực của giảng viên. Bên cạnh đó, công tác đào tạo kế toán phải phù hợp với sự phát triển của khoa học - công nghệ và sự phát triển của kinh tế tri thức vì vậy giảng viên phải là người am hiểu và thành thạo về các phần mềm kế toán giúp cho sinh viên tiếp cận với các phần mềm ngay khi còn đang học tập.

\section{KẾT LUẬN}

Trong bối cảnh nền giáo dục thế giới đang có những biến chuyển nhanh theo xu thế thời đại, đương đầu với sự cạnh tranh, các trường đại học ở Việt Nam đang đứng trước những vận hội, thời cơ và thách thức mới. Do vậy, đổi mới công tác đào tạo kế toán để tạo ra nguồn nhân lực có chất lượng cao đáp ứng yêu cầu hội nhập quốc tế là một yêu cầu cấp bách trong giai đoạn hiện nay. Tuy nhiên, để thực hiện được nhiệm vụ này không chỉ là sự nỗ lực, quyết tâm của các trường đại học, các giảng viên mà cần có sự phối các cơ quan quản lý, các tổ chức nghề nghiệp để mang lại sự thành công.

\section{TÀI LIỆU THAM KHẢO}

1. Karreman, G.H., (2007) -“Trends in Global Accounting Education”, Royal NIVRA, Amsterdam. In Royal Nirvia, Amsterdam, 1-136.

2. Green, D. (1994), "What is quality in higher education? Concepts, policy and practice", in Green, D (Ed.), What is Quality in Higher Education?, SRHE and Open University Press, Buckingham.

3. Srikanthan, G. and Dalrymymple, J. (2003), "Developing alternative perspectives for quality in higher education", The International Journal of Education Management, Vol. 17 No.3, pp. 126-136.

4. Verkruijsse, J.P.J. (2012), GAW 2012 Dynamic of Golbal Accountancy Education. $<$ http://www.accaglobal.com/conten/dam/acca/golbal/PDF-technical/other-PDFs/gae2012-dynamics-of-golbalaccountancy-education.pdf $>$. truy cập ngày 27/3/2017

5. Võ Văn Nhị, (2016), "Một số ý kiến về vấn đề đào tạo kế toán, kiểm toán bậc đại học đáp ứng xu thế hội nhập kinh tế quốc tế", Kỷ yếu hội thảo khoa học: Những xu hướng đổi mới trong nghiên cứu kế toán trên thế giới và yêu cầu đổi mới nội dung giảng dạy kế toán đối với các bậc đào tạo.

6. Đậu Thị Kim Thoa, (2016), "Những thách thức và định hướng đổi mới đào tạo kế toán bậc đại học tại Việt Nam theo tiêu chuẩn đào tạo quốc tế”, Kỷ yếu hội thảo khoa học: Những xu hướng đổi mới trong nghiên cứu kế toán trên thế giới và yêu cầu đổi mới nội dung giảng dạy kế toán đối với các bậc đào tạo.

7. Mai Thị Hoàng Minh,"Đổi mới công tác giảng dạy kế toán ở bậc đại học - khó khăn và thách thức."

8. Trương Bá Thanh - Trần Đình Khôi Nguyên, (1997), "Đổi mới công tác đào tạo kế toán - kiểm toán trong điều kiện hội nhập kinh tế thế giới”. <http://kh.due.udn.vn/ly_lich/chi_tiet/20>

9. Đặng Văn Thanh, (2011), Đổi mới chương trình, nội dung và các thức đào tạo kế toán - kiểm toán ở bậc đại học”, Kỷ yếu Hội thảo: Đổi mới công tác đào tạo kế toán, kiểm toán ở bậc đại học Việt Nam.

10. Nguyễn Thành Hải, Phùng Thúy Phượng, Đồng Thị Bích Thủy, (2010), "Giới thiệu một số phương pháp giảng dạy cải tiến giúp sinh viên học tập chủ động và trải nghiệm, đạt các chuẩn đầu ra theo CDIO”.

11. Đinh Tiến Minh, (2013), "Tìm hiểu về nghiên cứu khoa học và thực trạng hoạt động nghiên cứu khoa học của các trường đại học tại Việt Nam”

Ngày nhận bài: 10/11/2017

Ngày chấp nhận đăng: 12/03/2018 